\title{
Adalimumab and severe uveitis in juvenile idiopathic arthritis (JA)
} therapy

\author{
MG Alpigiani*1, A Calcagno ${ }^{1}$, R De Marco $^{2}$, M Haupt $^{1}$, P Salvati ${ }^{1}$, E Poggi ${ }^{1}$ \\ and R Lorini ${ }^{1}$
}

\author{
Address: ${ }^{1}$ Institute G. Gaslini, Department of Pediatrics, University of Genova, Genova, Liguria, Italy and ${ }^{2}$ Institute G. Gaslini, Department of \\ Ophthalmology, University of Genova, Genova, Liguria, Italy \\ * Corresponding author
}

\author{
from 15th Paediatric Rheumatology European Society (PreS) Congress \\ London, UK. 14-17 September 2008 \\ Published: 15 September 2008 \\ Pediatric Rheumatology 2008, 6(Suppl I):P76 doi:10.1 186/I546-0096-6-SI-P76
}

This abstract is available from: http://www.ped-rheum.com/content/6/SI/P76

(c) 2008 Alpigiani et al; licensee BioMed Central Ltd.

\section{Background}

Chronic anterior uveitis in JIA can be severe and common immunosuppressive therapies may not be sufficient to control uveitis. Concerning biological drugs, Enbrel is usually ineffective, Infliximab is partially effective and is frequently associated with side effects requiring drug suspension, while Adalimumab, a TNF competitor, can be successful.

\section{Methods}

We report on a girl aged 17 years, affected since one year by a severe form of poliarticular JIA. She received immunosuppressive therapy (Methotrexate, Azathioprine, etc.), associated with oral steroids, with no articular benefit.

\section{Results}

When Enbrel plus Methotrexate was started she got into remission. After one year of this therapy, she presented uveitis in both eyes, so oral steroids were started again. She obtained only partial ocular improvement, even when she received Infliximab associated with Methotrexate. Meantime she underwent cataract surgery with visus reduction. After one year, Infliximab was suspended because of an adverse reaction (dyspnea and rash) and Adalimumab $(0.7 \mathrm{mg} / \mathrm{kg}$ subcutaneous $/ 14$ days $)$ associated with Methotrexate was started, with no side effects. Fourteen months later there are no flare for uveitis and/or arthritis. Following SUN criteria [1] we demonstrated ocu- lar clinical improvement, not withstanding the presence of signs of cataract and glaucoma.

\section{Conclusion}

During the last ten years, biological drugs have been really useful to improve JIA outcome. In 2006 Biester S et al [2] showed Adalimumab efficacy in controlling arthritis and uveitis, with acceptable side effects, but further research is needed.

\section{References}

I. Jabs DA, et al:: Standardization of Uveitis Nomenclature for reporting clinical data. Am J Ophthalmol 2005, 140 (3):509-16.

2. Biester $S$, et al:: Adalimumab in the therapy of uveitis in childhood. BrJ Ophthalmol 2007, 9 I(3):274-6. 